\title{
EFFECT OF ENDURANCE EXERCISE ON RESTING TESTOSTERONE LEVELS IN SEDENTARY SUBJECTS
}

\author{
Ashira Hiruntrakul ${ }^{1}$, Ratanavadee Nanagara ${ }^{2}$, Alongkot Emasithi ${ }^{1}$, Katarina T. Borer ${ }^{3}$ \\ 'Department of Physiotherapy, Faculty of Associated Medical Science, Khon Kaen University, Thailand \\ 2Department of Medicine, Faculty of Medicine, Khon Kaen University, Thailand \\ ${ }^{3}$ Division of Kinesiology, Department of Movement Science, University of Michigan, Ann Arbor, USA
}

\section{SUMMARY}

Objective: To investigate the effects of moderate-intensity and low frequency exercise on resting serum testosterone and cortisol levels, resting heart rate, and isokinetic strength among healthy sedentary young men.

Design: A randomized controlled study. Forty sedentary young men aged 18 to 25 years old, pedaled 50 minutes on a bicycle ergometry at $60 \%$ of maximal effort once a week for 12 weeks in an exercise group.

Outcome measures: Resting total and free serum testosterone, serum cortisol, anthropometric data, resting heart rate, and isokinetic strength during shoulder and knee extensions.

Results: Resting serum total and free testosterone, as well as cortisol did not differ significantly between groups. Neither group showed any significant changes in anthropometric data and isokinetic strength at the end of study. However, the resting heart rate of the exercise group reduced significantly after the training $(p<0.05)$. Also, the isokinetic strength of shoulder and knee significantly increased $(p<0.05)$.

Conclusions: Twelve weeks of moderate-intensity and low frequency training had no effect on resting serum testosterone, but were sufficient to increase aerobic fitness among sedentary young men. The type of exercise training may encourage sedentary individuals to participate regularly in the program on physical activity.

Key words: testosterone, endurance exercise, strength, frequency

Address for correspondence: A. Hiruntrakul, Department of Physiotherapy, Faculty of Associated Medical Science, Khon Kaen University, Thailand. E-mail: hashir@ kku.ac.th

\section{INTRODUCTION}

Physical activity increases strength $(1,2)$ as well as aerobic fitness (3), alterates hormonal level (4-10), and decreases risks of cardiovascular morbidity and mortality (11-13). The influence of long-term physical training on hormonal response has been well established in athletes, but not yet among healthy sedentary men. Long-term physical training at moderate intensity 3 times a week, however, may possibly discourage the sedentary individuals to comply with the program. The drop-out rate is about 50\% during the first 6 to 12 months (15). The current recommendation for all healthy adults aged 18 to 65 years old is to engage in moderate-intensity aerobic physical activity for a minimum of 30 minutes 5 days each week, or vigorous-intensity aerobic physical activity for a minimum of 20 minutes 3 days each week (14). Undoubtedly, the effects of exercise also vary a great deal upon age and baseline fitness of the individuals. Generally, the benefits are more evident among the younger and unfitted individuals. As the prevalence of physically inactive adults is now increasing (16) rapidly, establishing a suitable exercise program to improve their hormonal level and fitness is quite crucial. They usually have low compliance and adherence to the generally recommended training programs. Therefore, the exercise program with low frequency perhaps fits better in their lifestyle and is easier to accomplish it for them. Based on the results of our pilot study (unpublished data), a moderateintensity exercise at frequency of once a week was enough to observe some changes in testosterone level after 12 weeks. The purpose of this study then was to investigate the effects of moderate-intensity and low frequency exercise training (1 hour, once a week) on serum testosterone, cortisol and lipid profiles, anthropometric data, and isokinetic strength in sedentary young men after 12 weeks.

\section{MATERIALS AND METHODS}

\section{Subjects}

Forty healthy sedentary men (mean age $20.8 \pm 1.85 \mathrm{yr}$ ) without cardiopulmonary, orthopedic, neurological or metabolic diseases were recruited. A sedentary status was defined as an individual who participated in any exercises less than 1 hour per week for at least 12 months prior to the beginning of this study. All subjects were informed verbally and in writing about the aim, protocol and demands of the study, and gave their written informed consents if they decided to participate. The study protocol was approved by the Khon Kaen University Ethics Committee for Human Research. Subjects were randomly assigned by simple drawing to either the exercise $(n=20)$ or the control group $(n=20)$. 
Table 1. Comparison parameters between the groups and time

\begin{tabular}{|l|c|c|c|c|}
\hline \multirow{2}{*}{ Parameters } & \multicolumn{2}{|c|}{ Exercise (N=19) } & \multicolumn{2}{c|}{ Control (N=18) } \\
\cline { 2 - 5 } & Before & After & Before & After \\
\hline Age $(\mathrm{yrs})$ & $21.00 \pm 2.00$ & $21.00 \pm 2.00$ & $20.00 \pm 1.00$ & $66.00 \pm 1.00$ \\
\hline Weight $(\mathrm{kg})$ & $61.73 \pm 10.94$ & $62.2 \pm 10.94$ & $65.72 \pm 11.16$ & $1.71 \pm 0.04$ \\
\hline Height $(\mathrm{cm})$ & $1.71 \pm 0.05$ & $1.71 \pm 0.05$ & $1.71 \pm 0.04$ & $22.47 \pm 3.58$ \\
\hline BMI $\left(\mathrm{kg} / \mathrm{m}^{2}\right)$ & $20.99 \pm 3.35$ & $21.20 \pm 2.90$ & $22.35 \pm 3.44$ & $8.78 \pm 6.08$ \\
\hline Percent fat & $6.52 \pm 4.34$ & $6.57 \pm 3.57$ & $7.89 \pm 4.76$ & $59.67 \pm 6.56$ \\
\hline FFM & $57.33 \pm 7.56$ & $57.97 \pm 7.20$ & $60.11 \pm 7.34$ & $0.82 \pm 0.08$ \\
\hline WHR & $0.80 \pm 0.05$ & $0.78 \pm 0.05$ & $0.81 \pm 0.07$ & $93 \pm 4.78 \dagger$ \\
\hline Resting Heart rate (bpm) & $88 \pm 3.76$ & $78 \pm 2.09 *$ & $90 \pm 3.65$ & $5.91 \pm 1.32$ \\
\hline Total testosterone (ng/cm $\left.{ }^{3}\right)$ & $5.32 \pm 1.62$ & $5.55 \pm 1.01$ & $5.44 \pm 1.24$ & $20.36 \pm 4.22$ \\
\hline Free testosterone (pg/cm $\left.{ }^{3}\right)$ & $20.76 \pm 6.25$ & $19.18 \pm 4.56$ & $18.93 \pm 4.39$ & $28.35 \pm 8.77$ \\
\hline Cortisol ( $\mu$ g/cm $\left.{ }^{3}\right)$ & $28.16 \pm 7.72$ & $27.14 \pm 7.96$ & $28.07 \pm 5.67$ & $52.00 \pm 11.11$ \\
\hline Shoulder flexion (watts) & $35.63 \pm 10.74$ & $44.74 \pm 11.33^{*}$ & $49.61 \pm 12.33$ & $67.61 \pm 15.04$ \\
\hline Shoulder extension (watts) & $53.42 \pm 17.86$ & $68.84 \pm 17.72^{*}$ & $66.61 \pm 14.20$ & $87.72 \pm 20.57$ \\
\hline Knee flexion (watts) & $66.63 \pm 17.39$ & $88.89 \pm 20.37^{*}$ & $80.50 \pm 27.09$ & $132.67 \pm 39.26$ \\
\hline Knee extension (watts) & $113.37 \pm 27.04$ & $137.05 \pm 29.13^{*}$ & $133.83 \pm 38.90$ & \\
\hline
\end{tabular}

* Difference from before training, $p<0.05$; † Difference from exercise group, $p<0.05$

\section{Study Protocol}

Before starting the exercise program, the anthropometric data, blood samples, and isokinetic strength of left knee and shoulder were obtained from all subjects. For the exercise group, subjects were scheduled to visit the exercise laboratory regularly once a week for 14 weeks. The first 2 visits were for familiarization with the exercise protocol, and the other 12 visits were training sessions. The training program consisted of a 5-minute warm up, a 50 -minute pedaling on a bicycle ergometer at $60 \% \mathrm{VO}_{2 \max }$, and a 5-minute cool down. For the control group, subjects were allowed to continue their regular life-style. Both groups were instructed not to change their dietary patterns and keep their diaries concerning their activities, stressful events, and food consumption during the whole training period and submitted it to researcher at the end. The anthropometric data, blood samples, and isokinetic strength were re-assessed at 14 weeks.

\section{Outcome Measures}

\section{Primary outcome variables}

Testosterone, cortisol, and lipid profiles. All subjects were asked to have overnight fast, refrain from alcohol, strenuous activity, and sexual activity 24 hours prior to the blood collection day. After 30-minute rest, a $15 \mathrm{~cm}^{3}$ of venous blood was drawn from the antecubital vein. The blood was allowed to clot at room temperature before being centrifuged. The serum was then kept frozen at $-85{ }^{\circ} \mathrm{C}$ for analyses. Total as well as free testosterone and cortisol were determined by the radioimmunoassay (RIA) at Medical Nuclear Unit, Department of Radiology, Faculty of Medicine, Khon Kaen University. Total testosterone was measured using the commercially available RIA kit (TESTO-CT2, CIS Bio International, France) with a lower limit of detection, inter- and intra-assay CVs of $0.1 \mathrm{ng} / \mathrm{cm}^{3}, 7 \%$, and $7.5 \%$, respectively. Free testosterone was analyzed by the RIA kit (DSL-4900, DSL Inc,
USA) with a lower limit of detection, inter- and intra-assay CVs of $0.18 \mathrm{pg} / \mathrm{cm}^{3}, 7.3 \%$, and $5.2 \%$, respectively. Cortisol was measured using the commercially available RIA kit (MP Biomedical, USA) with a lower limit of detection, inter- and intra-assay CVs of 0.17 $\mu \mathrm{g} / \mathrm{cm}^{3}, 7.6 \%$, and $6.1 \%$, respectively.

\section{Secondary outcome variables}

Anthropometric data. Skinfold thickness was measured by Lange calipers (Beta Technology, USA) at 7 standard sites to determine body fat. Percent body fat (\%BF), fat weight $(\mathrm{kg})$, and fat free mass $(\mathrm{kg})$ were calculated from body density $(\mathrm{Db})$, based on Jackson and Pollock (17) and Brozek's equations (18).

Muscle strength. Cybex 6000 dynamometer (Lumax Inc, NY, USA) was used to measure isokinetic strength of left knee and shoulder at the velocities of 90,120 and $180 \%$ sec. Three trials for each velocity with 20 seconds of rest in between. Peak torque as well as average power was recorded.

\section{Statistical Analysis}

All data were presented as mean \pm SD. A 2x2 (group x time) ANOVA was used to examine the effects of exercise on all dependent variables between 2 groups (exercise vs control) and times (before vs after). The statistics were analyzed using program SPSS, version 10 (SPSS Inc., Illinois, USA). The level of significance was set at $p<0.05$.

\section{RESULTS}

\section{Baseline Characteristics}

At baseline, subjects had comparable body weights, body mass indexes, waist-to-hip ratios, and blood plasma parameters (Table 1). 
The isokinetic strength of the control group was greater than the exercise group. (Table $1, p<0.05$ ). During the experimental period, 3 patients were unable to complete the training program: 1 (exercise group) and 2 (control group) withdrew for personal reasons.

After 12-week training. The level of resting serum total and free testosterone, as well as cortisol did not differ significantly between groups. Neither group showed any significant changes in body mass index, fat free mass, body fat, and waist/hip ratio. However, the resting heart rate of the exercise group reduced significantly after the training $(p<0.05)$. Also, the isokinetic strength of shoulder and knee significantly increased $(p<0.05)$. Isokinetic strength of shoulder flexion/extension and knee flexion/extension did not significantly differ between groups at the end of study.

\section{DISCUSSION}

This was a randomized controlled study examining the effects of moderate-intensity and low-frequency exercise on the testosterone level and general health status in sedentary young men. The results showed that both resting total and free testosterone levels did not statistically change despite a significant increase in arm and leg strength after the 12-week training program. The level of free testosterone, however, had tendency to decline. The similar findings have been reported in previous studies based on different population and training method (19-23). Up to date, the effects of exercise on the testosterone level remain controversial. Some studies reported a tremendous increase in the testosterone level after the moderate-intensity exercise lasting 45 to 90 minutes (1, $27,28)$, while others reported unchanged or slightly decreased testosterone concentration after exercise at the similar level and duration (19-23, 25, 26, 29). A decline in testosterone levels were also noted after moderate- to high-intensity exercise (31, 32). The duration and intensity of the program thus appear to play an important role. The possible explanations can be as follows. After initiating the submaximal exercise, the level of serum total testosterone is elevated by the hemoconcentration. Continuing the exercise causes more blood flow to the exercised muscles and less flow to the testicles. The hormonal secretion then starts to decline. In addition, the hepatic blood flow probably decreases as well followed by declining of the hepatic clearance. Therefore, the testosterone level may elevate once again. After a prolonged period of the exercise, the skeletal muscles are able to uptake a greater amount of hormone. Consequently, the testosterone level is gradually lessened. Several studies denoted that suppression of reproductive hormones in endurance-trained males may exist due to overtraining. A low level of resting testosterone in men after endurance training has some adverse affects on physiological processes related to androgenic-anabolic actions of testosterone such as decreased protein synthesis and muscle mass and favorable affects, the physiologic adaptations such as cardiovascular protective effects (33).

The exercise group also experienced an increase in muscle power of both upper and lower extremities after the training program (power $=86.71, \alpha=0.05$ ). It is possible that this group had poorer strength than the control group at the beginning of the program; therefore, the changes became more apparent. This was similar to previous reports $(2,38,39)$. Strength improvement after 12-week exercise, despite an unchanged testosterone level, may be due to changes in muscle fiber profile, metabolic adaptation, and neural recruitment in skeletal muscles (40-42). Unfortunately, we did not evaluate these parameters because they were not variables of interest in this study. Our results also indicated that the exercise group had minor increase in fat free mass (FFM), suggesting that training may alter hormonal environment (testosterone, growth hormone, catecholamine, etc) or hormone receptor density (e.g. androgen receptors) that possibly contribute to an increase in muscle strength $(43,44)$.

There was no significant improvement of BMI of the exercise group after training as all subjects were allowed to continue their dietary patterns. However, some positive effect on waist-hip ratio was observed even without statistical significance. This could be the result of an increase in fat free mass or a decrease in abdominal fat. Longer duration of the exercise program is most likely to bring more positive results.

The limitations of our study were the individual characteristics of subjects and duration of exercise. Our subjects were sedentary volunteers who prefer not to exercise even only once a week. However, this was a longitudinal controlled study in sedentary young men investigating the effects of exercise on serum testosterone level that could enroll more sample size compared to previous studies.

\section{CONCLUSION}

In summary, low-frequency (once a week) and moderateintensity exercise program did not affect the level of resting serum testosterone in sedentary young men after 12-week training. There were also some positive effects of this protocol on muscle strength and cardiovascular fitness. For that reason, the low-frequency and moderate-intensity exercise program is probably still beneficial for health promotion campaign in sedentary individuals who have poor compliance and adherence to the general exercise programs. Further study should examine if these beneficial effects were still present if more feasible exercise program is designed.

\section{Acknowledgements}

The authors thank all the subjects who volunteered for the study and greatly appreciate their time and cooperation. We acknowledge Dr. Temduang Limpaiboon, Dr. Chanvit Leelayuwat, and Dr. Thyon Chintanez for their assistance.

\section{REFERENCES}

1. Ahtiainen JP, Pakarinen A, Alen M, Kraemer WJ, Häkkinen K. Muscle hypertrophy, hormonal adaptations and strength development during strength training in strength-trained and untrained men. Eur J Appl Physiol. 2003 Aug;89(6):555-63.

2. McCaulley GO, McBride JM, Cormie P, Hudson MB, Nuzzo JL, Quindry JC, et al. Acute hormonal and neuromuscular responses to hypertrophy, strength and power type resistance exercise. Eur J Appl Physiol. 2009 Mar;105(5): 695-704.

3. Blomqvist CG, Saltin B. Cardiovascular adaptations to physical training. Annu Rev Physiol. 1983;45:169-89.

4. Myhal M, Lamb DR. Hormones as performance enhancing drugs. In: Warren MP, Constantini NW, editors. Sports endocrinology. Totowa: Humana Press; 2000. p. 433-76.

5. Cunha TS, Cunha NS, Moura MJ, Marcondes FK. Anabolic androgenic steroids and the relation to the sportive practice. Braz J Pharmac Sci. 2004;40(1):165-79. 
6. Vermeulen A. Clinical review 24: androgens in the aging male. J Clin Endocrinol Metab. 1991 Aug;73(2):221-4.

7. Häkkinen K, Pakarinen A, Alen M, Kauhanen H, Komi PV. Neuromuscular and hormonal adaptations in athletes to strength training in two years. J Appl Physiol. 1988 Dec;65(6):2406-12.

8. Kraemer WJ, Häkkinen K, Newton RU, Nindl BC, Volek JS, McCormick $\mathrm{M}$, et al. Effects of heavy-resistance training on hormonal response patterns in younger vs. older men. J Appl Physiol. 1999 Sep;87(3):982-92.

9. Pullinen T, Mero A, Huttunen P, Pakarinen A, Komi PV. Resistance exercise-induced hormonal responses in men, women, and pubescent boys. Med Sci Sports Exerc. 2002 May;34(5):806-13.

10. Jensen J, Oftebro H, Breigan B, Johnsson A, Ohlin K, Meen HD, et al. Comparison of changes in testosterone concentrations after strength and endurance exercise in well trained men. Eur J Appl Physiol Occup Physiol. 1991;63(6):467-71.

11. Lee IM, Skerrett PJ. Physical activity and all-cause mortality: what is the dose-response relation? Med Sci Sports Exerc. 2001 Jun;33(6 Suppl):S459-71; discussion S493-4.

12. Lee IM, Paffenbarger RS Jr. Preventing coronary heart disease: the role of physical activity. Phys Sportsmed. 2001 Feb;29(2):37-52.

13. Swain DP, Franklin BA. Comparison of cardioprotective benefits of vigorous versus moderate intensity aerobic exercise. Am J Cardiol. 2006 Jan 1;97(1):141-7.

14. Haskell WL, Lee IM, Pate RR, Powell KE, Blair SN, Franklin BA, et al; American College of Sports Medicine; American Heart Association. Physical activity and public health: updated recommendation for adults from the American College of Sports Medicine and the American Heart Association. Circulation. 2007 Aug 28;116(9):1081-93.

15. Dishman RK. Compliance/adherence in health-related exercise. Health Psychol. 1982;1(3):237-67.

16. European Commission. A pan-European survey on consumer attitudes to physical activity, body weight, and health. Luxembourg: Office for Official Publications of European Communities; 1999.

17. Jackson AS, Pollock ML. Prediction accuracy of body density, lean body weight, and total body volume equations. Med Sci Sports. 1977;9(4):197201

18. Brozek J, Grande F, Anderson JT, Keys A. Densitometric analysis of body composition: revision of some quantitative assumptions. Ann N Y Acad Sci. 1963 Sep 26;110:113-40.

19. Izquierdo M, Häkkinen K, Ibañez J, Garrues M, Antón A, Zúñiga A, et al. Effects of strength training on muscle power and serum hormones in middle-aged and older men. J Appl Physiol. 2001 Apr;90(4):1497-507.

20. Hoffman JR, Kang J, Ratamess NA, Faigenbaum AD. Biochemical and hormonal responses during an intercollegiate football season. Med Sci Sports Exerc. 2005 Jul;37(7):1237-41.

21. Kemmler W, Wildt L, Engelke K, Pintag R, Pavel M, Bracher B, et al. Acute hormonal responses of a high impact physical exercise session in early postmenopausal women. Eur J Appl Physiol. 2003 Sep;90(1-2):199209.

22. Harber MP, Fry AC, Rubin MR, Smith JC, Weiss LW. Skeletal muscle and hormonal adaptations to circuit weight training in untrained men. Scand J Med Sci Sports. 2004 Jun;14(3):176-85.

23. Bell GJ, Syrotuik D, Martin TP, Burnham R, Quinney HA. Effect of concurrent strength and endurance training on skeletal muscle properties and hormone concentrations in humans. Eur J Appl Physiol. 2000 Mar;81(5):418-27.

24. Viru A, Karelson K, Smirnova T. Stability and variability in hormonal responses to prolonged exercise. Int J Sports Med. 1992 Apr;13(3):230-5.

25. Hackney AC. The male reproductive system and endurance exercise. Med Sci Sports Exerc. 1996 Feb;28(2):180-9.

26. Wheeler GD, Wall SR, Belcastro AN, Cumming DC. Reduced serum testosterone and prolactin levels in male distance runners. JAMA. 1984 Jul 27;252(4):514-6.
27. Bonifazi M, Bela E, Carli G, Lodi L, Martelli G, Zhu B, et al. Influence of training on the response of androgen plasma concentrations to exercise in swimmers. Eur J Appl Physiol Occup Physiol. 1995;70(2):109-14.

28. Tremblay MS, Copeland JL, van Helder W. Influence of exercise duration on post-exercise steroid hormone responses in trained males. Eur J Appl Physiol. 2005 Aug;94(5-6):505-13.

29. Daly W, Seegers CA, Rubin DA, Dobridge JD, Hackney AC. Relationship between stress hormones and testosterone with prolonged endurance exercise. Eur J Appl Physiol. 2005 Jan;93(4):375-80.

30. Duclos M, Corcuff JB, Rashedi M, Fougere V, Manier G. Does functional alteration of the gonadotropic axis occur in endurance trained athletes during and after exercise? A preliminary study. Eur J Appl Physiol Occup Physiol. 1996;73(5):427-33.

31. Viru A. Hormonal ensemble in exercise: hormones in muscular activity. Volume 1. Boca Raton: CRC Press; 1985.

32. Galbo H. Hormonal and metabolic adaptation to exercise. New York: Georg Thieme Verlag; 1983

33. Blair SN, Kampert JB, Kohl HW 3rd, Barlow CE, Macera CA, Paffenbarger RS Jr, et al. Influences of cardiorespiratory fitness and other precursors on cardiovascular disease and all-cause mortality in men and women. JAMA. 1996 Jul 17;276(3):205-10.

34. Pollock ML, Ward A, Ayres JJ. Cardiorespiratory fitness: response to differing intensities and durations of training. Arch Phys Med Rehabil. 1977 Nov;58(11):467-73.

35. Wong PC, Chia MY, Tsou IY, Wansaicheong GK, Tan B, Wang JC, et al. Effects of a 12-week exercise training programme on aerobic fitness, body composition, blood lipids and C-reactive protein in adolescents with obesity. Ann Acad Med Singapore. 2008 Apr;37(4):286-93.

36. Womack CJ, Davis SE, Blumer JL, Barrett E, Weltman AL, Gaesser GA. Slow component of O2 uptake during heavy exercise: adaptation to endurance training. J Appl Physiol. 1995 Sep;79(3):838-45.

37. Scheuermann BW, Barstow TJ. O2 uptake kinetics during exercise at peak O2 uptake. J Appl Physiol. 2003 Nov;95(5):2014-22.

38. Cadore EL, Lhullier FL, Brentano MA, da Silva EM, Ambrosini MB, Spinelli R, et al. Hormonal responses to resistance exercise in long-term trained and untrained middle-aged men. J Strength Cond Res. 2008 Sep;22(5):1617-24.

39. Xu DQ, Hong Y, Li JX. Tai Chi exercise and muscle strength and endurance in older people. Med Sport Sci. 2008;52:20-9.

40. Häkkinen K, Kallinen M, Linnamo V, Pastinen UM, Newton RU, Kraemer WJ. Neuromuscular adaptations during bilateral versus unilateral strength training in middle-aged and elderly men and women. Acta Physiol Scand. 1996 Sep;158(1):77-88.

41. Häkkinen K, Kallinen M, Izquierdo M, Jokelainen K, Lassila H, Mälkiä E, et al. Changes in agonist-antagonist EMG, muscle CSA, and force during strength training in middle-aged and older people. J Appl Physiol. 1998 Apr;84(4):1341-9.

42. Pyka G, Taaffe DR, Marcus R. Effect of a sustained program of resistance training on the acute growth hormone response to resistance exercise in older adults. Horm Metab Res. 1994 Jul;26(7):330-3.

43. Antonio J, Wilson JD, George FW. Effects of castration and androgen treatment on androgen-receptor levels in rat skeletal muscles. J Appl Physiol. 1999 Dec;87(6):2016-9.

44. Kadi F, Bonnerud P, Eriksson A, Thornell LE. The expression of androgen receptors in human neck and limb muscles: effects of training and selfadministration of androgenic-anabolic steroids. Histochem Cell Biol. 2000 Jan;113(1):25-9. 